\title{
Senescence and p130/Rbl2: a new beginning to the end
}

\author{
Francesco P Fiorentino ${ }^{1,2}$, Catherine E Symonds ${ }^{2}$, Marcella Macaluso ${ }^{2}$, Antonio Giordano ${ }^{2,3}$
}

${ }^{I}$ Section of Medical Oncology, Department of Oncology, Regional Reference Center for the Biomolecular Characterization and Genetic Screening of Hereditary Tumors, Università di Palermo, Via del Vespro 127, 90127, Palermo, Italy; ${ }^{2}$ Department of Biology, Sbarro Institute for Cancer Research and Molecular Medicine, Center for Biotechnology, College of Science and Technology, Temple University, BioLife Science Bldg. Suite 333, 1900 N 12th Street, Philadelphia, Pennsylvania 19122, USA; ${ }^{3}$ Department of Human Pathology and Oncology, University of Siena, Siena, Italy

Senescence is the process of cellular aging dependent on the normal physiological functions of non-immortalized cells. With increasing data being uncovered in this field, the complex molecular web regulating senescence is gradually being unraveled. Recent studies have suggested two main phases of senescence, the triggering of senescence and the maintenance of senescence. Each has been supported by data implying precise roles for DNA methyltransferases, reactive oxygen species and other factors. We will first summarize the data supporting these claims and then highlight the specific role that we hypothesize that $\mathbf{p} 130 / \mathrm{Rbl} 2$ plays in the modulation of the senescence process.

Keywords: Rb family, senescence, DNMT, p130/Rb12, cell cycle

Cell Research (2009) 19:1044-1051. doi:10.1038/cr.2009.96; published online 11 August 2009

\section{Introduction}

Senescence, the process of cellular aging, was initially described as the permanent cell cycle arrest that accompanied the replicative exhaustion of cultured human fibroblasts [1]. It differs from quiescence, which is defined as a temporary cell cycle arrest, readily reversible in response to proliferative conditions, and is believed to play a role in both in vivo aging and cancer [2-8]. Senescent cells are marked by characteristic changes in morphology, remain metabolically active and will not revert to proliferation even under promitogenic conditions $[6,9]$. Senescence has been heavily studied in vitro and in vivo, and while much has been learnt since Hayflick's initial observation, we are still far from fully understanding the molecular intricacies of this physiological phenomenon.

Telomere shortening, a normal physiological function that occurs during cellular duplication, is a driving force behind the activation of the senescence pathway [1014]. Senescence can also be triggered by stresses, such as DNA-damaging agents, oncogene activation or altered chromatin organization [15-17]. These stresses all have

Correspondence: Antonio Giordano

Tel: 215-204-9520; Fax: 215-204-9522

E-mail: giordano@temple.edu the potential to initiate or promote neoplastic transformation, pointing to the importance of understanding senescence on a clinical level.

Senescence, being an end point to the cell cycle, has largely been investigated through the study of cell cycle regulatory genes. The retinoblastoma $(\mathrm{Rb})$ family proteins together with respective E2F factors are critical in the progression and control of the cell cycle, specifically in the progression from $\mathrm{G}_{0}$ to $\mathrm{S}$ phase [18]. Moreover, the role of $\mathrm{Rb}$ family proteins as critical effectors of cellular senescence has widely been discussed during recent years [19-23]. Three proteins, p105/Rb, p107 and p130/ $\mathrm{Rbl2}$, constitute the $\mathrm{Rb}$ family and are characterized by a pocket domain involved in protein-protein interaction [24].

Unlike other $\mathrm{Rb}$ family member proteins, $\mathrm{p} 130 / \mathrm{Rbl} 2$ is active in $\mathrm{G}_{0}$-arrested cells, where it forms a complex with E2F-4 [18]. This complex binds DNA and modulates E2F target genes $[25,26]$. In response to mitogenic stimuli, p130/Rbl2 is inactivated by cyclin-dependent kinases (CDKs) $[25,26]$. This allows E2F factors to activate E2F target genes, allowing the cell cycle to proceed (Figure 1) $[27,28]$. On the contrary, under cellular stresses, such as DNA damage, CDKs are inhibited by CDK inhibitors and $\mathrm{Rb}$ members remain active, thus arresting cell cycle progression $[27,28]$. While the role of $\mathrm{p} 130 / \mathrm{Rbl} 2$ as the specific $\mathrm{Rb}$ member involved in senescence in response 
to CDK-inhibition and the functional compensation by other $\mathrm{Rb}$ family members in cells lacking functional p130/Rb12 have already been discussed (Figure 1) [19, 21-23], there are now suggestions for a role of $\mathrm{p} 130 / \mathrm{Rbl} 2$ during the initiation, or triggering, of the senescence process.

In this review, we summarize the molecular process of senescence, dividing it into two separate temporal phases, and introduce our hypothesis of a novel role for p130/ Rbl2 during the triggering of senescence as suggested by recent literature.

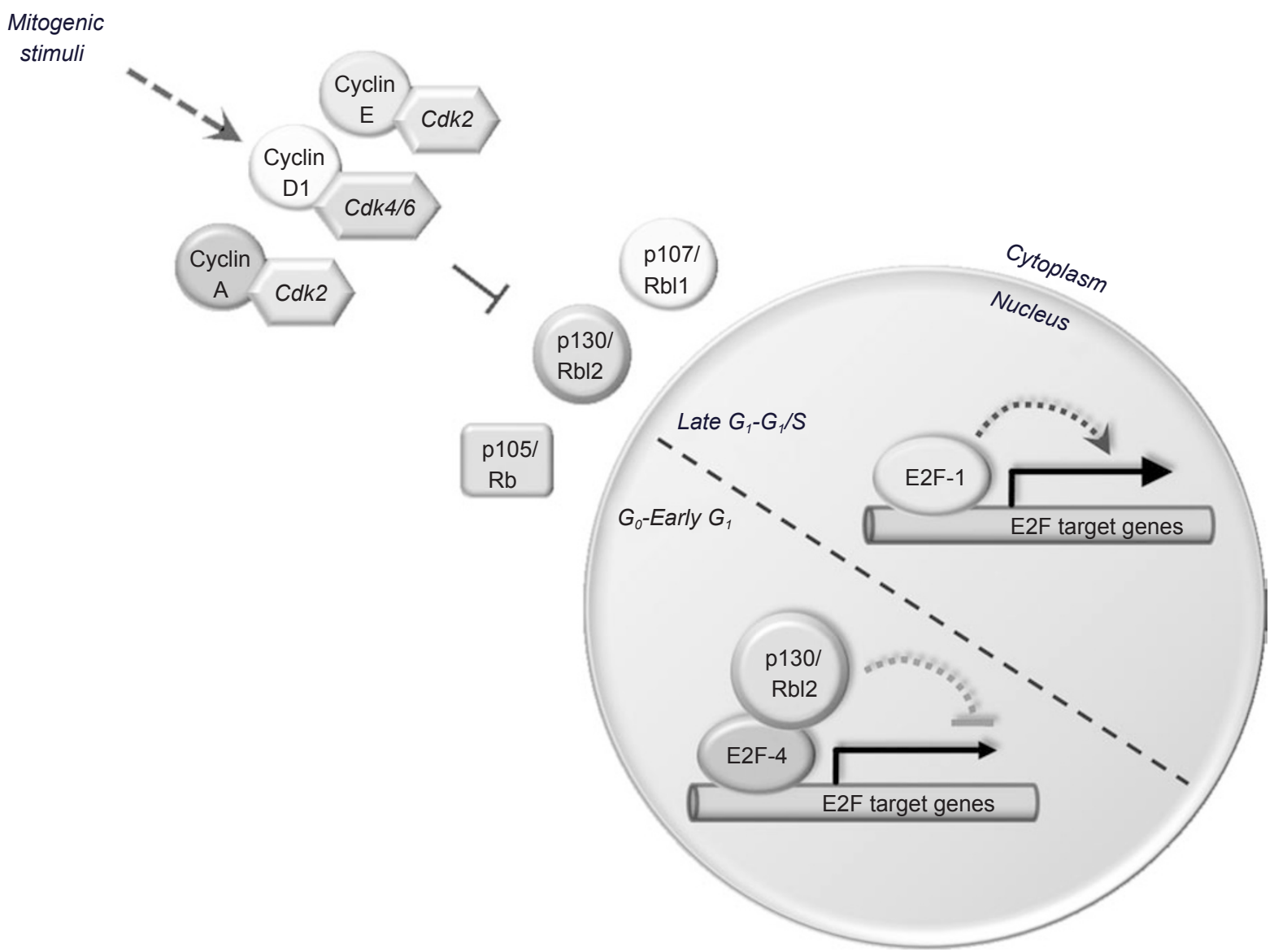

\section{Two distinct phases in the senescence process}

Senescence, a process more complex than originally thought, involves both physiological and morphological changes to the cells $[6,9]$. Our purpose is not to clarify all molecular mechanisms involved and studied in senescence, but to give an overview of the process, focusing on telomere signaling and the pathways involved in its response. For a more complete and detailed explanation of the entire process and all the pathways involved, we suggest three recent manuscripts by Muller et al., Fridman and Tainsky, and Cichowski and Hahn [6, 29,

Figure 1 Differential regulation of E2F target genes during $G_{0}-G_{1} / S$ progression. In $G_{0}$ and early $G_{1}$ phase, the complex $p 130 /$ Rbl2-E2F-4 binds to and represses E2F target genes. In late $G_{1}$ and $G_{1} / S$ phase, E2F target genes are activated by the E2F-1 factor, which replaces the p130/Rbl2-E2F-4 complex [26]. The transition of complexes is mediated by mitogenic stimuli, which activate cyclin-CDK complexes that in turn phosphorylate and inhibit Rb family members [18]. Different studies have indicated that the three $\mathrm{pRb}$ family members exhibit a functional overlap, although not a complete redundancy, in many aspects of cell regulation. p107 and p130/Rbl2 appear to be redundant in regulating a specific set of E2F-responsive genes that are not subject to $\mathrm{pRb} / \mathrm{E} 2 \mathrm{~F}-$-mediated repression [76-78]. Interestingly, it has been shown that $\mathrm{Rb}^{-/-} \mathrm{p} 107^{-/}$murine embryonic fibroblasts (MEFs), although initially subject to growth inhibition, did not enter senescence but established a constant proliferation rate. Furthermore, ablation of all Rb-gene family members renders these cells virtually insensitive to growth inhibition and strongly increases their proliferation rate, indicating a predominant role of $\mathrm{Rb}$ family in cellular senescence [22, 23]. 
30]. To better understand the role of $\mathrm{p} 130 / \mathrm{Rbl} 2$ in the regulation of senescence, we propose to divide the process into two distinct phases differing on timing and molecular pathways implied. We term the initial phase as the triggering of senescence, where cells stop dividing but remain metabolically active. This phase is characterized by a burst in the expression of $\mathrm{p} 21^{\mathrm{CIP} 1}$, which then diminishes as senescence continues, both in vitro and in vivo [31-33]. During this phase cells will express a characteristic senescent phenotype, which is, however, reversible [34]. The second phase, which we term as the maintenance of senescence, occurs once the cells pass the critical midpoint and become irreversibly arrested [34, 35]. This phase is characterized by the accumulation of p16 ${ }^{\mathrm{INK4A}}$, which has been shown to uniquely occur during late senescence $[31,32,35,36]$. Both $\mathrm{p} 21^{\mathrm{ClP} 1}$ and $\mathrm{p} 16^{\mathrm{INK} 4 \mathrm{a}}$ are independently able to induce inhibition of the activity of cyclin-CDK complexes, thus modulating the hypophosphorylation of $\mathrm{Rb}$ family members and $\mathrm{E} 2 \mathrm{~F}$ target gene expression $[6,27,32,36,37]$. We believe that the distinction between these two phases could be important, as diverse molecular pathways have been shown to be involved. Nonetheless it is significant to recognize them as phases of a unique process, acting concurrently or in response to one another. However, there are also data supporting the view that the two pathways are independently activated and regulated instead by the timing of events during senescence $[38,39]$. While both theories are currently valid, we propose that there exists a midpoint during senescence that divides these two phases.

\section{The triggering of senescence: telomere shortening, p53 activation and $\mathrm{p} 21^{\mathrm{CIP} 1}$ accumulation}

Triggering of senescence has the role of both decreasing cellular proliferation, as well as preparing the cell to cease duplication and maintain its senescent state. The initiation of senescence is believed to be triggered, in physiological conditions, when progressive telomere shortening leads to the activation of p53 [40-42]. Telomere shortening is sensed as DNA damage and is recognized by ataxia telangiectasia mutated (ATM) protein [42]. When ATM senses that there is DNA damage, it phosphorylates histone $\mathrm{H} 2 \mathrm{AX}(\gamma-\mathrm{H} 2 \mathrm{AX})$, which is found at the site of damage. It then recruits TRF1 and TRF2 followed by Chk1 and Chk2 [38, 43], leading to the activation of p53 and senescence (Figure 2).

Cyclin-Cdk complexes are critical in continuing the progression of the cell cycle. They inhibit $\mathrm{Rb}$ family member proteins allowing E2F factors to bind and initiate transcription of cell cycle-promoting genes [44]. The activation of $\mathrm{p} 53$, a critical transcription factor involved in cell cycle control pathways, leads to the transcription of CDKN1A gene and accumulation of $\mathrm{p} 21^{\mathrm{CIP} 1}$ in senescent cells [45]. p2 $1^{\mathrm{CIP} 1}$ binds to and inhibits the cyclinCdk complexes as well as the proliferating cell nuclear antigen (PCNA) through complex formation, thus regulating cell cycle progression, DNA synthesis and DNA repair (Figure 2) [6, 32, 46-51].

Telomere shortening continues to be a topic of great interest, given its initiating role in senescence, but much is yet to be discovered. Gonzalo et al. [52] have shown that defects in DNA methyltransferases (DNMTs) lead to decreased methylation of subtelomeric regions and elongated telomere length in mouse embryonic stem cells. Benetti et al. [53] further show that overexpression of DNMTs can rescue DNA methylation in subtelomeric regions of DICER ${ }^{--}$mouse embryonic stem cells. The precise role of DNMTs in the regulation of telomere length remains to be defined, but DNMTs seem to be implicated in telomere shortening as well as in the triggering of senescence $[54,55]$. The principal human DNMTs are hDNMT1, hDNMT3a and hDNMT3b [56-58]. Zheng et al. [54] have shown that protein levels of DNMT1 and DNMT3a increase from young to middle-aged human fibroblasts but decrease in senescent fibroblasts. Moreover, in non-senescent cells DNMTs methylate the promoter of $\mathrm{p} 21^{\mathrm{CIP} 1}$, repressing its transcription [54, 55].

The implication of DNMTs in the triggering of senescence, given the data presented, could be suggested by the two following scenarios (Figure 2). First, they could act as promoters of progressive telomere shortening, leading to the activation of the p53 pathway $[52,53]$. Second, they could act as transcriptional repressors of CDKN1A gene, modulating $\mathrm{p} 21^{\mathrm{CIP} 1}$ transcription $[54,55]$. It is interesting to note that while the level of DNMTs increases in middle-aged human fibroblasts, it decreases in senescent fibroblasts $[54,59]$. This supports the role of DNMTs both in progressive telomere shortening in non-senescent cells and the subsequent activation of CDKN1A transcription in senescent cells.

During senescence, the regulation of DNMTs likely involves p130/Rbl2 (Figure 2). Benetti et al. [53] have shown that in DICER ${ }^{-1-}$ mouse ES cells, where there is an increase in p130/Rbl2 transcript, there is an aberrant elongation of telomeres caused by decreased levels of DNMT3a and DNMT3b. Transfection of the miR-290 cluster, which is involved in the silencing of $\mathrm{p} 130 / \mathrm{Rbl}$, has been shown to rescue DNMT levels. The direct involvement of $\mathrm{p} 130 / \mathrm{Rb} 2$ in the triggering of senescence is supported by an intriguing result by Lehmann et al. [60], where silencing of $\mathrm{p} 130 / \mathrm{Rbl} 2$ in $\mathrm{p} 105 / \mathrm{Rb}^{-/-}$cells led to premature senescence, while silencing of p107/Rbll led to resistance of irradiation-induced senescence. The spe- 


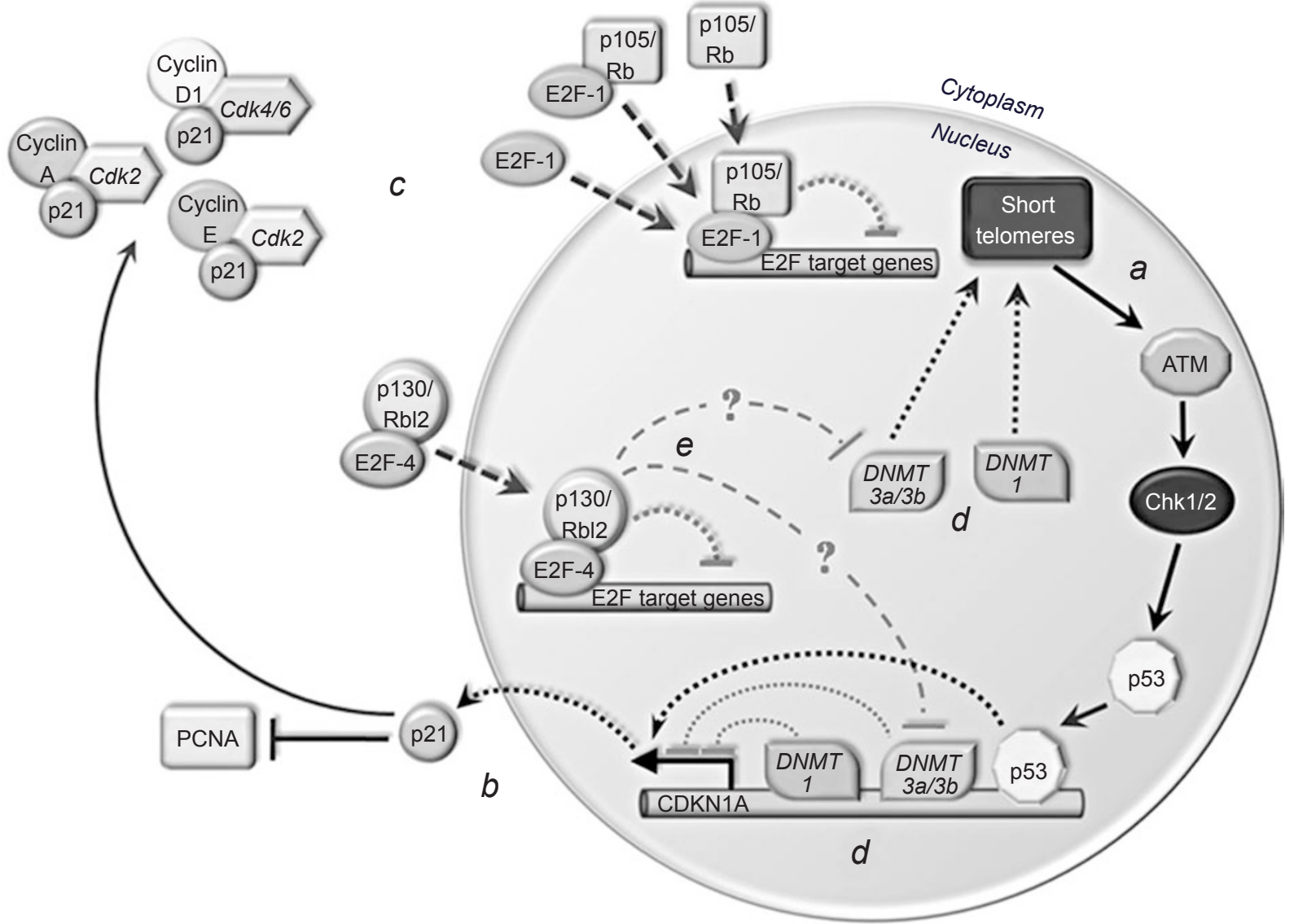

Figure 2 Progressive telomere shortening leads to the activation of the senescence pathway. Short telomeres are sensed by ATM, or by ATR in $\mathrm{ATM}^{-/}$cells [38], as DNA damage, which activates p53 (a). p53, acting as a transcriptional activator of CDKN1A gene, leads to the activation of $\mathrm{p} 21^{\mathrm{ClP} 1}$ (b), which binds to cyclin-CDK complexes, blocking their enzyme activity [45-51]. As a result, $\mathrm{Rb}$ members cannot be phosphorylated and inactivated by cyclin-CDK complexes, leading to cell cycle arrest (c) [44]. Recent studies suggest that DNMTs could be implicated in the activation of the senescence process through the methylation of subtelomeric regions leading to progressive telomere shortening $[52,53]$, and through transcriptional repression of CDKN1A gene, modulating $\mathrm{p} 21^{\mathrm{CIP} 1}$ transcription [54] (d). These contrary functional regulations could be understood as a "control mechanism". In fact, when DNMTs are silenced and telomere shortening is compromised, the transcription of CDKN1A still leads to premature senescence in human cells [55]. Benetti et al. [53] have also shown that p130/Rbl2 could have a specific role in telomere length regulation through the modulation of DNMT levels, specifically DNMT3a and DNMT3b (e).

cific role of $\mathrm{p} 130 / \mathrm{Rbl2}$, but not other Rb family proteins, in the regulation of DNMTs could explain this. It could then be hypothesized that the silencing of $\mathrm{p} 130 / \mathrm{Rbl} 2$ would accelerate telomere shortening through deregulation of DNMTs, thus triggering senescence. These are only observations and must be confirmed through further studies; however, the role of p130/Rbl2 in telomere shortening and in the triggering of senescence is strongly suggested.

\section{The maintenance of senescence}

The maintenance of senescence is still not well de- fined. The main effector seems to be $16^{\mathrm{INK} 4 \mathrm{a}}$, inhibitor of Cyclin D-associated kinases [61, 62], which is able to independently induce senescence $[31,36,63]$. While its exact role is not completely understood, it is believed to be involved in the maintenance of cell cycle arrest during the senescence process, because it accumulates in late senescence [32] and its expression and function are independent of telomere status $[64,65]$. p16 ${ }^{\mathrm{INK} 4 \mathrm{a}}$ maintains the activity of $\mathrm{Rb}$ family members by preventing cyclin D1 from forming complexes with CDKs 4 and 6, which are initially responsible for $\mathrm{Rb}$ family inhibition [31]. Beauséjour et al. [34] have shown that proliferating cells with $\mathrm{p} 16^{\mathrm{INK} 4 \mathrm{a}}$ stably silenced can proceed into senescence; 


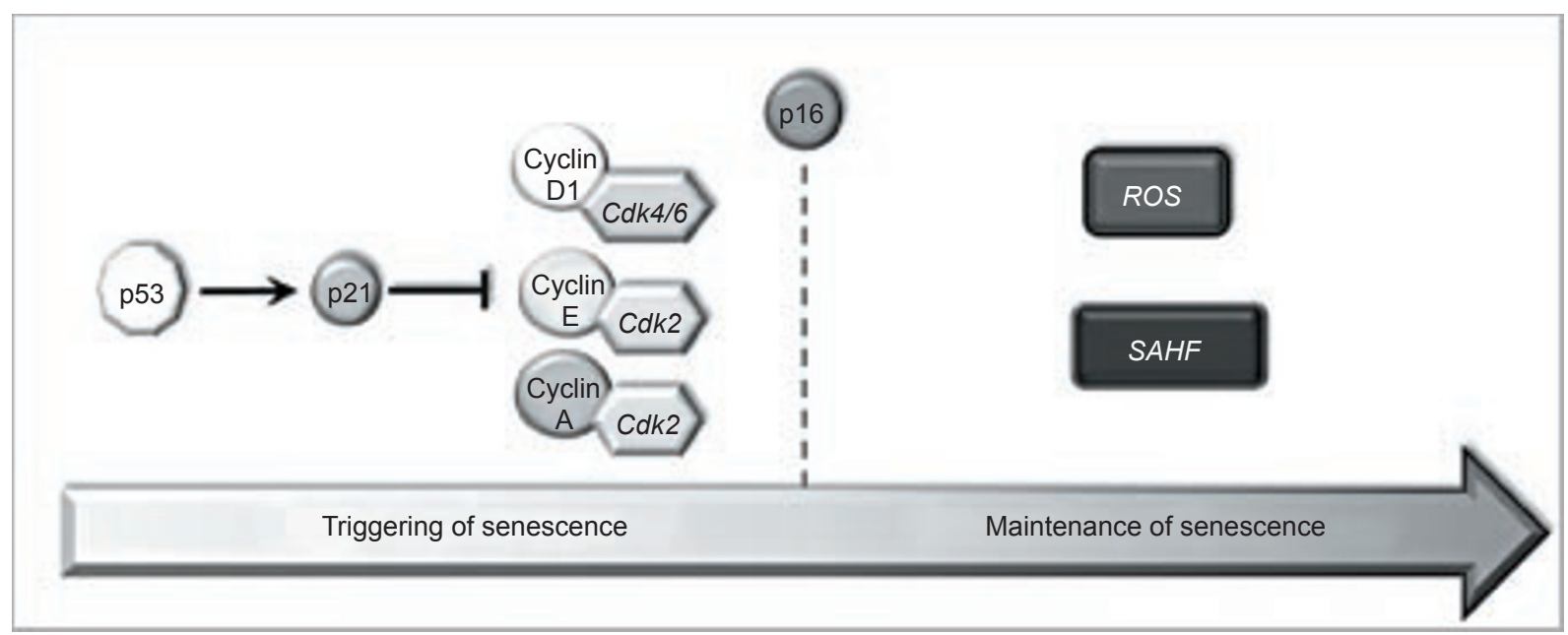

Figure 3 p16 $6^{\mathrm{INK} 4 \mathrm{a}}$ activation of maintenance of senescence. The maintenance of senescence is obtained after the cell surpasses the "midpoint", regulated by the $\mathrm{p} 16^{\text {INK4a }} / \mathrm{Rb}$ pathway [33]. Once this occurs, cells cannot "go back". It is suggested that this irreversible state is caused by two processes, both of which represent consequences of the $\mathrm{p} 16^{\mathrm{INK} 4 \mathrm{a}} / \mathrm{Rb}$ pathway: the formation of irriversibly silenced senescence-associated heterochromatic foci (SAHF) [20, 66-72] and the production of reactive oxygen species (ROS) that maintain their levels through a positive feedback mechanism [73].

however, they maintain elevated levels of $\mathrm{p} 21^{\mathrm{CIP} 1}$, and the subsequent suppression of p53 can completely reverse the senescent phenotype. Instead, if $16^{\mathrm{INK} 4 \mathrm{a}}$ is stably silenced after the cells have entered senescence, then suppression of p53 cannot reverse the senescent phenotype.

Evidence suggests a specific role for the $\mathrm{p} 16^{\mathrm{INK} 4 a} /$ $\mathrm{Rb}$ pathway in the formation of senescence-associated heterochromatic foci (SAHF), a heterochromatic DNA structure that accumulates in senescent human cells [20, 66-68]. First, Rb interacts with the histone methylase, Suv39H1, which methylates lysine 9 of histone H3 (K9M-H3) and forms a complex with methyl-lysine binding protein, HP1, in the promoter region of E2F target genes, resulting in transcriptional repression, which is coincident with SAHF formation in senescence cells [20, $69,70]$. In fact, SAHF, which are rich in K9M-H3 and $\mathrm{HP} 1$, are induced by enforced $\mathrm{p} 16^{\mathrm{INK} 4 \mathrm{a}}$ expression and are reduced by suppression of $\mathrm{p} 16^{\mathrm{INK} 4 \mathrm{a}}$ or $\mathrm{p} 105 / \mathrm{Rb}[20]$. Second, $\mathrm{p} 16^{\text {INK4a }} / \mathrm{Rb}$ cooperate with the ASF1a/HIRA pathway to drive chromosome condensation and SAHF formation $[68,71,72]$.

Recently, it has been shown that once senescence becomes irreversible, there is a $16^{\mathrm{INK} 4 \mathrm{a}}$-dependent activation of reactive oxygen species (ROS), which maintain their levels through a $16^{\mathrm{INK} 4 \mathrm{a}}$-independent positive feedback mechanism $[35,73]$. The role of ROS in senescence remains unknown, as do many other aspects of the senescence process. However, there is now suggestion for a $16^{\mathrm{INK} 4 \mathrm{a}}$-dependent midpoint in the senescence process, which leads to both SAHF formation and activation of
ROS production. Once the midpoint is surpassed, independently from $\mathrm{p} 16^{\mathrm{INK} 4 \mathrm{a}}$ levels, it would no longer be possible for the cell to return to "youth" (Figure 3).

\section{Conclusion}

The role of $\mathrm{Rb}$ family members in senescence has yet to be clearly defined. It is known that all $\mathrm{Rb}$ family members are implicated in the senescence process, but there are suggestions for a specific role of $\mathrm{p} 130 / \mathrm{Rb} 2$ that does not simply represent the compensation of p105/Rb $[19$, 21]. Recently, it has been shown that downregulation of $\mathrm{p} 130 / \mathrm{Rb} 2$ by siRNA in $\mathrm{p} 105 / \mathrm{Rb}^{-/-}$cells caused premature senescence [60], instead of prolonged life as would be expected if p130/Rbl2 acted in substitution of p105/ $\mathrm{Rb}$. To better understand the different roles of proteins that share similar structure and function, it is important to understand the interactions with their respective effector molecules. E2F-1, E2F-2 and E2F-3 can be bound by $\mathrm{p} 105 / \mathrm{Rb}$ and are present only after mitogenic stimuli, whereas E2F-4, bound by p130/Rb12, is much more abundant and functional in $\mathrm{G}_{0}$-arrested cells than other E2F factors [35, 74, 75]. During senescence, $\mathrm{Rb}$ members block the transcriptional activity of E2F factors [1921]. p130/Rbl2 on the other hand, is hypothesized to play a specific role in the triggering of senescence through its regulation of DNMTs [53]. The premature senescence found in p130/Rbl2-silenced cells could be explained by an excessive presence of DNMTs that could facilitate the shortening of telomeres $[53,60]$. 
While it is understood that $\mathrm{p} 130 / \mathrm{Rb} 2$ plays an important role in cell cycle arrest, taking a critical look at the current literature suggests evidence supporting its unique role in cellular senescence. Here we have attempted to analyze how its role could be implicated given the current literature. Furthermore, we have discussed the evidence for a specific midpoint in senescence that determines whether the cell can revert back into the cell cycle or can only remain senescent and proceed toward cell death. Clearly, additional studies are needed to elucidate the entire senescence pathway and the specifics of p130/ $\mathrm{Rb} 12$ function. The senescence process includes various pathways and is indeed a complex molecular mechanism that is only beginning to be appreciated in recent years.

\section{Acknowledgments}

We acknowledge the support by US Army Medical Research grant (Sbarro Health Research Organization, \#06062003) and NIH grant (\#CA060999) to A Giordano.

\section{References}

1 Hayflick L. The limited in vitro lifetime of human diploid cell strains. Exp Cell Res 1965; 37:614-636.

2 Dimri G, Lee X, Basile G, et al. A biomarker that identifies senescent human cells in culture and in aging skin in vivo. Proc Natl Acad Sci USA 1995; 92:9363-9367.

3 Herbig U, Ferreira M, Condel L, Carey D, Sedivy J. Cellular senescence in aging primates. Science 2006; 311:1257.

4 Campisi J. Cellular senescence as a tumor-suppressor mechanism. Trends Cell Biol 2001; 11:S27-S31.

5 Sarkisian C, Keister B, Stairs D, et al. Dose-dependent oncogene-induced senescence in vivo and its evasion during mammary tumorigenesis. Nat Cell Biol 2007; 9:493-505.

6 Muller M. Cellular senescence: molecular mechanisms, in vivo significance, and redox considerations. Antioxid Redox Signal 2009; 11:59-98.

7 Jeyapalan J, Sedivy J. Cellular senescence and organismal aging. Mech Ageing Dev 2008; 129:467-474.

8 Jeyapalan J, Ferreira M, Sedivy J, Herbig U. Accumulation of senescent cells in mitotic tissue of aging primates. Mech Ageing Dev 2007; 128:36-44.

9 Dimri G, Testori A, Acosta M, Campisi J. Replicative senescence, aging and growth-regulatory transcription factors. Biol Signals 1996; 5:154-162.

10 Harley C, Futcher A, Greider C. Telomeres shorten during ageing of human fibroblasts. Nature 1990; 345:458-460.

11 Blackburn E. Switching and signaling at the telomere. Cell 2001; 106:661-673.

12 Kim Sh S, Kaminker P, Campisi J. Telomeres, aging and cancer: in search of a happy ending. Oncogene 2002; 21:503-511.

13 Shay J, Wright W. Ageing and cancer: the telomere and telomerase connection. Novartis Found Symp 2001; 235:116-125; discussion 125-129, 146-149.

14 de Lange T. Cell biology. Telomere capping--one strand fits all. Science 2001; 292:1075-1076.
15 Campisi J, d'Adda di Fagagna F. Cellular senescence: when bad things happen to good cells. Nat Rev Mol Cell Biol 2007; 8:729-740.

16 Nakagawa H, Opitz O. Inducing cellular senescence using defined genetic elements. Methods Mol Biol 2007; 371:167-178.

17 Bihani T, Chicas A, Lo C, Lin A. Dissecting the senescencelike program in tumor cells activated by Ras signaling. $J$ Biol Chem 2007; 282:2666-2675.

18 Sun A, Bagella L, Tutton S, Romano G, Giordano A. From G0 to $S$ phase: a view of the roles played by the retinoblastoma $(\mathrm{Rb})$ family members in the Rb-E2F pathway. J Cell Biochem 2007; 102:1400-1404.

19 Kapić A, Helmbold H, Reimer R, et al. Cooperation between p53 and p130(Rb12) in induction of cellular senescence. Cell Death Differ 2006; 13:324-334.

20 Narita M, Nũnez S, Heard E, et al. Rb-mediated heterochromatin formation and silencing of E2F target genes during cellular senescence. Cell 2003; 113:703-716.

21 Helmbold H, Deppert W, Bohn W. Regulation of cellular senescence by Rbl2/p130. Oncogene 2006; 25:5257-5262.

22 Sage J, Mulligan GJ, Attardi LD, et al. Targeted disruption of the three Rb-related genes leads to loss of G(1) control and immortalization. Genes Dev 2000; 14:3037-3050.

23 Dannenberg JH, van Rossum A, Schuijff L, te Riele H. Ablation of the retinoblastoma gene family deregulates $\mathrm{G}(1)$ control causing immortalization and increased cell turnover under growth-restricting conditions. Genes Dev 2000; 14:3051-3064.

24 Classon M, Dyson N. p107 and p130: versatile proteins with interesting pockets. Exp Cell Res 2001; 264:135-147.

25 Rayman J, Takahashi Y, Indjeian V, et al. E2F mediates cell cycle-dependent transcriptional repression in vivo by recruitment of an HDAC1/mSin3B corepressor complex. Genes Dev 2002; 16:933-947.

26 Takahashi Y, Rayman J, Dynlacht B. Analysis of promoter binding by the E2F and $\mathrm{pRB}$ families in vivo: distinct $\mathrm{E} 2 \mathrm{~F}$ proteins mediate activation and repression. Genes Dev 2000; 14:804-816.

27 Weinberg R. The retinoblastoma protein and cell cycle control. Cell 1995; 81:323-330.

28 Dimova D, Dyson N. The E2F transcriptional network: old acquaintances with new faces. Oncogene 2005; 24:2810-2826.

29 Fridman A, Tainsky M. Critical pathways in cellular senescence and immortalization revealed by gene expression profiling. Oncogene 2008; 27:5975-5987.

30 Cichowski K, Hahn W. Unexpected pieces to the senescence puzzle. Cell 2008; 133:958-961.

31 Alcorta D, Xiong Y, Phelps D, et al. Involvement of the cyclindependent kinase inhibitor p16 (INK4a) in replicative senescence of normal human fibroblasts. Proc Natl Acad Sci USA 1996; 93:13742-13747.

32 Stein G, Drullinger L, Soulard A, Dulić V. Differential roles for cyclin-dependent kinase inhibitors p21 and p16 in the mechanisms of senescence and differentiation in human fibroblasts. Mol Cell Biol 1999; 19:2109-2117.

33 Ohtani N, Imamura Y, Yamakoshi K, et al. Visualizing the dynamics of p21(Waf1/Cip1) cyclin dependent kinase inhibitor expression in living animals. Proc Natl Acad Sci USA 2007; 104:15034-15039.

34 Beauséjour C, Krtolica A, Galimi F, et al. Reversal of human 
cellular senescence: roles of the p53 and p16 pathways. EMBO J 2003; 22:4212-4222.

35 Takahashi A, Ohtani N, Yamakoshi K, et al. Mitogenic signalling and the p16INK4a-Rb pathway cooperate to enforce irreversible cellular senescence. Nat Cell Biol 2006; 8:1291-1297.

36 Hara E, Smith R, Parry D, et al. Regulation of p16CDKN2 expression and its implications for cell immortalization and senescence. Mol Cell Biol 1996; 16:859-867.

37 Dimri GP, Nakanishi M, Desprez PY, Smith JR, Campisi J. Inhibition of E2F activity by the cyclin-dependent protein kinase inhibitor p21 in cells expressing or lacking a functional retinoblastoma protein. Mol Cell Biol 1996; 16:2987-2997.

38 Herbig U, Jobling W, Chen B, Chen D, Sedivy J. Telomere shortening triggers senescence of human cells through a pathway involving ATM, p53, and p21(CIP1), but not p16(INK4a). Mol Cell 2004; 14:501-513.

39 Herbig U, Sedivy J. Regulation of growth arrest in senescence: telomere damage is not the end of the story. Mech Ageing Dev 2006; 127:16-24.

40 Itahana K, Dimri G, Campisi J. Regulation of cellular senescence by p53. Eur J Biochem 2001; 268:2784-2791.

41 von Zglinicki T, Saretzki G, Ladhoff J, d'Adda di Fagagna F, Jackson S. Human cell senescence as a DNA damage response. Mech Ageing Dev 2005; 126:111-117.

42 d'Adda di Fagagna F, Reaper P, Clay-Farrace L, et al. A DNA damage checkpoint response in telomere-initiated senescence. Nature 2003; 426:194-198.

43 Shiloh Y. ATM and related protein kinases: safeguarding genome integrity. Nat Rev Cancer 2003; 3:155-168.

44 Sherr C, Roberts J. CDK inhibitors: positive and negative regulators of G1-phase progression. Genes Dev 1999; 13:15011512.

45 Jackson J, Pereira-Smith O. p53 is preferentially recruited to the promoters of growth arrest genes p21 and GADD45 during replicative senescence of normal human fibroblasts. Cancer Res 2006; 66:8356-8360.

46 Noda A, Ning Y, Venable S, Pereira-Smith O, Smith J. Cloning of senescent cell-derived inhibitors of DNA synthesis using an expression screen. Exp Cell Res 1994; 211:90-98.

47 Hill R, Leidal A, Madureira P, et al. Hypersensitivity to chromium-induced DNA damage correlates with constitutive deregulation of upstream p53 kinases in p21 $1^{-/ 2}$ HCT116 colon cancer cells. DNA Repair (Amst) 2008; 7:239-252.

48 Furuta T, Hayward R, Meng L, et al. p21CDKN1A allows the repair of replication-mediated DNA double-strand breaks induced by topoisomerase I and is inactivated by the checkpoint kinase inhibitor 7-hydroxystaurosporine. Oncogene 2006; 25:2839-2849.

49 Waga S, Hannon G, Beach D, Stillman B. The p21 inhibitor of cyclin-dependent kinases controls DNA replication by interaction with PCNA. Nature 1994; 369:574-578.

50 Zhang H, Xiong Y, Beach D. Proliferating cell nuclear antigen and p21 are components of multiple cell cycle kinase complexes. Mol Biol Cell 1993; 4:897-906.

51 Viale A, De Franco F, Orleth A, et al. Cell-cycle restriction limits DNA damage and maintains self-renewal of leukaemia stem cells. Nature 2009; 457:51-56.

52 Gonzalo S, Jaco I, Fraga M, et al. DNA methyltransferases control telomere length and telomere recombination in mam- malian cells. Nat Cell Biol 2006; 8:416-424.

53 Benetti R, Gonzalo S, Jaco I, et al. A mammalian microRNA cluster controls DNA methylation and telomere recombination via Rbl2-dependent regulation of DNA methyltransferases. Nat Struct Mol Biol 2008; 15:268-279.

54 Zheng Q, Ma L, Zhu W, Zhang Z, Tong T. p21Waf1/Cip1 plays a critical role in modulating senescence through changes of DNA methylation. $J$ Cell Biochem 2006; 98:1230-1248.

55 Young J, Smith J. DNA methyltransferase inhibition in normal human fibroblasts induces a p21-dependent cell cycle withdrawal. J Biol Chem 2001; 276:19610-19616.

56 Pradhan S, Bacolla A, Wells R, Roberts R. Recombinant human DNA (cytosine-5) methyltransferase. I. Expression, purification, and comparison of de novo and maintenance methylation. J Biol Chem 1999; 274:33002-33010.

57 Okano M, Bell D, Haber D, Li E. DNA methyltransferases Dnmt3a and Dnmt3b are essential for de novo methylation and mammalian development. Cell 1999; 99:247-257.

58 Kim G, Ni J, Kelesoglu N, Roberts R, Pradhan S. Co-operation and communication between the human maintenance and de novo DNA (cytosine-5) methyltransferases. EMBO J 2002; 21:4183-4195.

59 Zhang W, Ji W, Yang J, et al. Comparison of global DNA methylation profiles in replicative versus premature senescence. Life Sci 2008; 83:475-480.

60 Lehmann B, Brooks A, Paine M, et al. Distinct roles for p107 and p130 in Rb-independent cellular senescence. Cell Cycle 2008; 7:1262-1268.

61 Serrano M, Hannon G, Beach D. A new regulatory motif in cell-cycle control causing specific inhibition of cyclin D/ CDK4. Nature 1993; 366:704-707.

62 Sherr C. G1 phase progression: cycling on cue. Cell 1994; 79:551-555.

63 Brookes S, Rowe J, Ruas M, et al. INK4a-deficient human diploid fibroblasts are resistant to RAS-induced senescence. EMBO J 2002; 21:2936-2945.

64 Kiyono T, Foster S, Koop J, et al. Both Rb/p16INK4a inactivation and telomerase activity are required to immortalize human epithelial cells. Nature 1998; 396:84-88.

65 Rheinwald J, Hahn W, Ramsey M, et al. A two-stage, p16(INK4A)- and p53-dependent keratinocyte senescence mechanism that limits replicative potential independent of telomere status. Mol Cell Biol 2002; 22:5157-5172.

66 Narita M, Krizhanovsky V, Nuñez S, et al. A novel role for high-mobility group a proteins in cellular senescence and heterochromatin formation. Cell 2006; 126:503-514.

67 Funayama R, Saito M, Tanobe H, Ishikawa F. Loss of linker histone H1 in cellular senescence. J Cell Biol 2006; 175:869880 .

68 Adams PD. Remodeling of chromatin structure in senescent cells and its potential impact on tumor suppression and aging. Gene 2007; 397:84-93.

69 Nielsen SJ, Schneider R, Bauer UM, et al. Rb targets histone H3 methylation and HP1 to promoters. Nature 2001; 412:561565.

70 Vandel L, Nicolas E, Vaute O, Ferreira R, Ait-Si-Ali S, Trouche D. Transcriptional repression by the retinoblastoma protein through the recruitment of a histone methyltransferase. Mol Cell Biol 2001; 21:6484-6494. 
71 Ye X, Zerlanko B, Zhang R, et al. Definition of pRB- and p53dependent and -independent steps in HIRA/ASF1a-mediated formation of senescence-associated heterochromatin foci. Mol Cell Biol 2007; 27:2452-2465.

72 Funayama R, Ishikawa F. Cellular senescence and chromatin structure. Chromosoma 2007; 116:431-440.

73 Ramsey M, Sharpless N. ROS as a tumour suppressor? Nat Cell Biol 2006; 8:1213-1215.

74 Good L, Dimri G, Campisi J, Chen K. Regulation of dihydrofolate reductase gene expression and E2F components in human diploid fibroblasts during growth and senescence. $J$ Cell Physiol 1996; 168:580-588.
75 Sardet C, Vidal M, Cobrinik D, et al. E2F-4 and E2F-5, two members of the E2F family, are expressed in the early phases of the cell cycle. Proc Natl Acad Sci USA 1995; 92:2403-2407.

76 Herrera RE, Sah VP, Williams BO, Mäkelä TP, Weinberg RA, Jacks T. Altered cell cycle kinetics, gene expression, and G1 restriction point regulation in Rb-deficient fibroblasts. Mol Cell Biol 1996; 16:2402-2407.

77 Hurford R, Cobrinik D, Lee M, Dyson N. pRB and p107/p130 are required for the regulated expression of different sets of E2F responsive genes. Genes Dev 1997; 11:1447-1463.

78 Mulligan G, Jacks T. The retinoblastoma gene family: cousins with overlapping interests. Trends Genet 1998; 14:223-229. 